\title{
Socioeconomic Determinants of Cardiovascular Disease: Recent Findings and Future Directions
}

\author{
M. Maria Glymour • Cheryl R. Clark • Kristen K. Patton
}

Published online: 11 April 2014

(C) Springer International Publishing AG 2014

\begin{abstract}
Socioeconomic advantage predicts lower risk of cardiovascular disease (CVD), but the magnitude of socioeconomic inequalities changes over time and differs between countries. The malleability of socioeconomic inequalities suggests that closing the socioeconomic status (SES) gap in CVD may be a powerful avenue for reducing the global CVD burden. Current evidence indicates that effects of socioeconomic disadvantage accumulate across the life course, with each additional period of disadvantage increasing later CVD risk. Individual, community, and national socioeconomic conditions appear to independently predict development of conventional risk factors and CVD. To translate this evidence into effective public-health interventions, we need more conclusive evidence on the causal components of highly correlated socioeconomic measures and on the major mediators of inequalities.
\end{abstract}

Keywords Socioeconomic factors $\cdot$ Inequality $\cdot$ Health disparities $\cdot$ Social class $\cdot$ Epidemiology $\cdot$ Lifecourse . Education $\cdot$ Cross-national comparisons $\cdot$ Neighborhood effects

\footnotetext{
M. M. Glymour ( $\varangle)$

Department of Epidemiology \& Biostatistics, University of California, San Francisco, 185 Berry Street, Suite 5700,

San Francisco, CA 94107, USA

e-mail:mglymour@epi.ucsf.edu

C. R. Clark

Division of General Medicine \& Primary Care, Center for Community Health and Health Equity, Brigham and Women's Hospital, 1620 Tremont Street, Boston, MA 02120, USA

e-mail: crclark@partners.org

K. K. Patton

Department of Medicine, University of Washington, 1959 NE Pacific

Street, Seattle, WA 98195, USA

e-mail: krisp@cardiology.washington.edu
}

\section{Introduction}

The large and pervasive social inequalities in cardiovascular disease (CVD) represent both a vexing problem and a major public health opportunity [1]. Despite countless publications on hypothesized pathways linking socioeconomic disadvantage and cardiovascular risk, we still do not know the best strategies to eliminate those inequalities. If we can solve this puzzle and identify successful interventions to close the gap, the public health achievement will be enormous. Galea et al. [2] estimated that reducing the all-cause mortality rate of United States adults with less than high-school education to be the same as the mortality rates of adults who had completed high school would have resulted in 244,526 fewer deaths in the year 2000. Closing the gap in all-cause mortality associated with poverty would save an additional 133,250 lives. Cardiovascular diseases account for a large fraction of these premature deaths. Does the current epidemiologic evidence support the premise that socioeconomic inequalities in CVD are preventable? This review emphasizes the following points:

- Socioeconomic and geographic inequalities prevail for incidence, prevalence, and mortality of a broad range of cardiovascular health outcomes, such that disadvantaged individuals have higher CVD rates [1].

- Inequalities in CVD risk begin to emerge in early life; physiologic changes may initiate even before birth, but conditions at later ages, including adolescence, are probably also especially influential for certain pathways. Addressing inequalities will thus require that we consider how risk in one stage of life shapes risk at later ages [3].

- Inequalities persist across time and are manifest in most countries. Both the absolute and relative magnitude of inequalities, however, have evolved over the past century and differ across countries. The changing pattern of inequalities and crossnational differences indicate that reductions in inequalities in CVD are achievable [4-6]. 
- Our best current evidence indicates that inequalities are partially but not fully accounted for by differences in health behaviors such as smoking or physical activity. Thus, even if low socioeconomic status (SES) individuals adopted the behavioral profiles of high SES individuals, large inequalities would persist [7, 8]. Eliminating socioeconomic inequalities will likely require addressing both behavioral and non-behavioral pathways.

- The health behaviors that partially mediate socioeconomic effects are not simply individual decisions, but rather are profoundly shaped by social and physical environments [9-11, 12•]. Identifying behavioral predictors of CVD is only a first step in eliminating inequalities, because healthy behaviors are driven by a complex web of determinants. To eliminate inequalities, we must understand why behavioral patterns systematically differ between socioeconomic groups and across geographic regions.

In this review, we briefly summarize some of the recent literature on socioeconomic inequalities in CVD (myocardial infarction [MI], heart failure [HF], and stroke), along the dimensions of geography, timing in the life course, and in recent historical contexts. We discuss only incidentally several closely related topics, including racial and ethnic inequalities in CVD [13, 14 •]; psychosocial mediators of SES inequalities (e.g., psychological stress, emotions, mental health, social isolation or social integration) [15-17]; and SES gradients in CVD risk factors (hypertension, inflammatory biomarkers) [18]. Focused discussion of these topics is beyond the scope of the current review, except to the extent that these inequalities mediate or are mediated by socioeconomic determinants. For example, there are marked socioeconomic inequalities between racial and ethnic groups in the United States, as well as stark residential segregation; socioeconomic and geographic inequalities thus relate closely to racial disparities [19]. African Americans in the US on average inherit less wealth, receive less education and lower quality education, are offered lower status jobs and paid lower wages, live in disadvantaged urban neighborhoods or in the less healthy southern region of the country, and experience more discrimination than whites. Although there is tremendous heterogeneity both within and between ethnic groups, these pervasive socioeconomic differences contribute to racial disparities.

We discuss leading hypotheses regarding the mechanisms generating socioeconomic and geographic inequalities in CVD. We also assess the most promising areas for future research, including both quasi-experimental and intervention studies. To date, the largest research bases are available for MI, HF, and stroke and closely related conditions, so we emphasize these outcomes. However, we note that intriguing evidence is also emerging for other outcomes, such as arrhythmic disorders [20].

\section{What is Socioeconomic Status (SES)?}

SES is commonly measured as educational attainment, income, or occupational class. These factors likely have immediate and direct consequences for cardiovascular risk but are also understood to be correlates of a host of other indicators of advantage. As public health researchers, we adopt a pragmatic definition of socioeconomic status that draws on Link and Phelan's 'Fundamental Cause' theory [21, 22]. Fundamental Cause theory posits that SES is a flexible resource that individuals deploy as needed to pursue various goals; in particular, goals that improve their health. For example, higher levels of education provide individuals with higher earnings (on average), which can be used to purchase resources such as better healthcare and healthier food, and which can enable more leisure time for exercise. Higher levels of education and income also tend to improve social standing and status: highly educated and wealthier individuals are less likely to be subject to everyday hassles and humiliations which low-income people commonly encounter in inter-personal or institutional interactions. SES also influences health through social networks, because highly educated individuals tend to have highly educated spouses, friends, acquaintances, and children. These social networks set beneficial behavioral norms, provide resources, obtain and share information, and provide material and emotional support [16]. Finally, education in particular may enable individuals to take advantage of new evidence on health-promoting behaviors or treatments. As a result, Fundamental Cause theory implies that technological innovations in care may exacerbate inequalities, as high SES individuals are the first to benefit from such improvements [21, 23].

\section{Life-Course Models}

As with other health risk factors, recent research suggests that SES may have different effects on individuals at different life stages, either because of physiologically sensitive developmental periods (e.g., gestation) or socially defined periods of vulnerability or rapid transition (e.g., the peri-bereavement period) [3, 24, 25-27]. Thus, measuring SES comprehensively would entail assessment throughout the life course. A growing body of research focuses on evidence for competing models of how the timing and duration of socioeconomic disadvantage influence long-term health outcomes. For example, researchers and clinical practitioners often implicitly assume that people will immediately benefit from the removal of a negative exposure. This 'immediate risk' model is plausible for certain exposures, like toxic pharmaceutical combinations. For socioeconomic factors, however, the etiologic period is likely to be much longer. We know, for example, that individuals born in the southeastern US 'stroke belt' are at higher risk of stroke even decades after they migrate away from this 
region $[28 \bullet, 29,30]$. Similarly, individuals who experienced disadvantage in early life due to low parental SES — regardless of their own adult SES - have elevated risk of cardiovascular disease, including diabetes mellitus, heart disease, stroke, and hypertension at older ages $[3,25,31]$. These findings indicate that events or exposures in early life may have an enduring influence on risk. One possible explanation is that early-life disadvantage is just one of many influences in a long and accumulating sequence of risk factors, with each period of exposure to disadvantage adding to risk [32]. Such a 'cumulative' model implies that the earlier interventions are targeted, the more benefit they could have, but even interventions in late life could still be beneficial.

A competing model suggests that risk does not accumulate, but rather that exposures have disproportionate influence during a brief developmental window. After those critical or sensitive developmental periods conclude, this model posits that episodes of disadvantage or advantage have limited additional impact. Evidence supports the existence of sensitive developmental windows, but the picture is muddied because various studies implicate the importance of different developmental windows. For example, a large body of research suggests that low birth weight predicts a host of adult cardiovascular endpoints [33].

However, other research emphasizes behavioral risk factors, such as smoking. Smoking initiation typically occurs in adolescence and initiation after age 30 is unusual, whereas cessation rates increase at older ages [34]. Thus, smoking prevalence among international immigrants reflect the smoking rates of the country in which they lived during adolescence $[35,36]$. Similarly, among immigrant adults, age at arrival also predicts overweight and obesity risk [37]. For these behavioral risk factors, adolescence may be the most sensitive period.

Given current evidence, it seems likely that although there may well be critical or sensitive periods for specific mechanisms, there are multiple mechanisms linking SES to CVD. These various mechanisms have different sensitive periods, and in combination, a cumulative risk model best describes the link between SES and CVD. In other words, early-life socioeconomic disadvantage has impacts over and above adolescent or adult SES, but these later time periods add to the adverse effects.

Some research posits that it is change in SES between early life and adulthood that puts individuals at risk, i.e., social mobility is a risk factor. Some flavors of this model appear to be equivalent to 'immediate risk': if downward mobility is unhealthy, and upward mobility is healthy, this effectively implies that it is adult SES that is most relevant for CVD risk. However, sometimes the mobility model is framed as arising from 'status inconsistency', which would imply that change in either direction is unhealthy (i.e., an interaction between childhood and adult SES). Although this possibility is theoretically plausible, studies of mobility per se have reported fairly inconsistent results to date and are not compelling based on current evidence [38].

Distinguishing between 'immediate', 'critical period', and 'cumulative' risk models is essential because these alternatives should guide specific actions that could plausibly reduce socioeconomic inequalities in health. For example, using a particular model might shape our understanding about whether interventions must occur early in an individual's life or whether they could be beneficial much later, at ages when CVD is typically diagnosed. However, empirically testing the models against one another is technically challenging. Early efforts to test life-course theories used regression models that could not distinguish between immediate, critical period, and cumulative risk effects; this challenge was exacerbated by imperfect measurement of SES. An important advance came with formalization of regression models that test the models against one another [39॰]. An additional technical challenge arises because many risk factors that are confounders of adult SES (and therefore must be controlled when estimating adult SES effects) are likely to be mediators of childhood SES influences (and therefore must not be controlled when estimating childhood SES effects). In this situation, conventional mediation models will tend to understate the effect of childhood SES. Only recently have analytic tools appropriate for such complex sequences of exposure been adopted [31, 40] and they are not widespread in life-course epidemiology.

\section{Scales of SES Measurement}

In addition to differential impacts throughout the life course, SES may be defined as an individual characteristic (e.g., own education), as a family variable (household income), as a community indicator (neighborhood percent poverty), or as a state or regional variable (state, regional, or national differences in per capita income). In some cases, measurement at one level is used as a proxy for another level. For example, it is common to use neighborhood SES as a proxy for individual SES, because these two variables are strongly correlated. However, several lines of research indicate that multiple levels may be independently predictive of important CVD risk factors. For example, neighborhood characteristics predict health-risk behaviors such as diet and physical activity, as well as cardiovascular outcomes [41-43], independent of the individual SES of neighborhood residents. Illustrative exceptions occur for residents of immigrant enclaves, because, for example, immigrants often adhere to advantageous diets of their countries of origin [44]. Thus, it has been found that individuals residing in high immigrant concentration neighborhoods in some cases have better healthy food availability, but fewer opportunities for recreational exercise. In contrast, many low-income communities lack high-quality grocery 
stores or other retail venues to purchase healthy foods [45]. This lack presumably changes the foods people are likely to purchase and consume, but is not necessarily a reflection of individual preference for less healthy foods. Interviews with people in 'food deserts' indicate they prefer a healthy diet as much as people in middle-class neighborhoods [46].

Good measurement of SES at individual, family, and community levels remains a major challenge. At an individual level, early-life SES is often measured based on parental SES. Education is an appealing measure because it is typically established by early adulthood and remains stable throughout the remainder of life. Income and occupational class are clearly dynamic and change substantially from early adulthood to middle-age, and into retirement and late old age. Neighborhood SES is often measured as average neighborhood poverty or income rates, but the meaning of 'neighborhood' is heterogeneous. Analyses are typically based on administrative boundaries, which are imperfect proxies for the places in which people live their lives [47]. Furthermore, neighborhoods may not be the most relevant 'place' for all ages: for example, children spend many of their waking hours in schools, and adults spend many of their waking hours in workplaces. Neighborhood SES may be less relevant than SES in these other settings. Workplaces and schools, along with other routinely encountered settings such as churches, retail outlets, or clinical-care providers, may provide more promising venues for intervention because such organizations typically have an organized set of policies $[48,9]$.

\section{Recent Studies of Cardiovascular Disease (CVD) Related to SES, Place, and Time}

In a comprehensive review of SES gradients and CVD risk over 20 years ago, Kaplan and Keil summarized the already overwhelming evidence that socioeconomic disadvantage predicts higher risk of CVD [1]. In the past two decades, extensive work has generally confirmed these findings for a host of CVD outcomes, including MI, stroke, and HF. Recent work, including major systematic reviews and meta-analyses, has elaborated on contexts in which SES inequalities are larger or smaller [4, 49-52]. SES gradients in CVD are most consistent in high-income countries.

In a 2011 meta-analysis of SES gradients in the incidence of acute MI comparing high- and middle- or low-income countries, Manrique-Garcia and colleagues [4] analyzed 70 case-control and cohort studies published between 1966 and 2009. SES gradients in incident MI were more pronounced in high-income countries than in middle- and low-income countries. Incident acute MI was associated with education, occupation, and income, but the analysis identified a high degree of heterogeneity across study results, and some evidence of publication bias for studies focusing on income and occupation as measures of SES. Although the weaker associations in low- and middle-income countries may partially reflect the limited data availability, the findings are consistent with earlier results from the INTERHEART study [53].

Social gradients in major risk factors such as smoking and obesity have changed rapidly in many countries and in general are sharper in high-income or highly urbanized countries [54, 55]. As economic development progresses, high-SES individuals may be in a better position to take advantage of resources to prevent CVD, whereas low SES individuals adopt the highly marketed, unhealthy behaviors of high-income countries, thereby exacerbating inequality. The pervasiveness of this phenomenon is controversial, in part because of the data limitations. Subramanian et al. [56] argued that CVD risk factors remained a much greater burden on socioeconomically advantaged individuals in India. This claim was contested by Stringhini and Bovet [57], who argued that anticipating the potential explosion of CVD associated with the epidemiologic transition should motivate and guide immediate action in lowand middle-income countries. However, even if we embrace Stringhini and Bovet's perspective, it may not be entirely obvious what action to take. Mackenbach characterizes the persistence of socioeconomic inequalities in health in highincome countries with sophisticated social welfare policies as a paradox, in that substantial improvements in the material conditions of the most disadvantaged in these countries does not appear to have eliminated CVD inequalities [58].

Globally, large between-country and within-country differences in stroke have also been documented, such that residents of low-income countries have a higher burden of stroke compared with residents of high-income countries, and low-SES individuals have a higher burden of stroke than high-SES individuals in the same country [59]. A recent review of the worldwide impact of SES on stroke incidence and mortality, including data from the 1970 s to 2008 , found that low-income countries had approximately 3.5 -fold higher rates of strokerelated mortality and disability-adjusted life-years lost compared with middle- and high-income countries. The trend of declining stroke incidence observed in high-income countries stands in marked contrast to the experience of low- and middle-income countries, which have experienced substantial increases in stroke incidence in recent decades [52, 59]. Analogous results, showing large SES inequalities, were found in a systematic review of SES gradients in HF incidence and mortality [49]. Gradients in SES and material deprivation measured in mid-to-late adulthood were associated with an increased incidence of HF in cohorts in Denmark, the US, Europe and the UK [49].

In seeking to understand the role of socioeconomic inequities in changes in disease rates and mortality, Harper et al. [60] describe heterogeneity in educational differences in CVD mortality across time, CVD subtype, and by country of study. In general, across many high-income countries, as CVD 
mortality declined, relative socioeconomic inequalities widened. However, such relative inequalities may be of less importance than absolute inequalities in health, which have often narrowed. In their review of the data on early-life socioeconomic factors and CVD, the authors suggest a stronger effect of childhood SES in studies that prospectively assess childhood exposures compared with those using retrospective assessments, with additional heterogeneity in the strength of associations seen by subtype of CVD, and measure of SES used [60].

Several recent economic trends in the US present opportunities and challenges for studying relations between SES gradients and CVD outcomes. In particular, the great recession of 2007-2009 re-focused attention on the issue of income inequality. As an example, a recent study of Medicare beneficiaries hospitalized with diagnoses of acute MI or HF during the recession explored income inequality as a potential determinant of 30-day mortality and 30-day hospital readmission [61]. The authors found no association between state-level income inequality and mortality from acute MI, but a small reverse association between high income inequality and 30day HF mortality. Risk of 30-day readmission was increased in areas of high income inequality for both MI and HF [61]. An important challenge in such studies is the possibility of residual confounding at the state level. Greater income inequality, for example, was found to be associated with a higher percentage of the state population living below the federal poverty level. Additional studies using longitudinal time-series and difference-in-difference analyses may enhance understanding of the causal influences of inequality and other macro-level factors on CVD risk.

In research on temporal trends in SES gradients in CVD, changes in underlying economic conditions introduce methodological challenges in the ability to estimate causal effects of SES. Chen and colleagues [62] conducted an elegant set of simulations demonstrating the difficulties in comparing time trends in relationships between SES and health when only a single indicator of SES is used to capture SES gradients, but the underlying population distribution of other aspects of SES are changing over time. The authors discuss methods for estimating the degree to which changes in the population distribution of single SES indicators affect the estimation of causal effects, for example, as the value of a high-school education changes. At a minimum, the authors suggest using multiple indicators of SES in time trend analyses, and comparing how SES gradients change for each indicator over time [62].

\section{Mechanisms Linking SES to CVD}

Several features of the link between SES and CVD guide current thinking about mechanisms. First, SES inequalities cannot be fully explained by differences in medical access, because inequalities prevail even in countries or populations with essentially equal access to high-quality medical care [63]. Second, the association is not limited to extremely deprived individuals, but shows a gradient across socioeconomic levels. For example, in the landmark Whitehall study of British civil servants, each successive increase in rank was associated with lower CVD risk, even though no participants were in extreme poverty [64]. This finding suggests that although material deprivation per se may contribute to socioeconomic inequalities, it is not sufficient to explain the social gradient. This seminal finding has elicited a host of research on how psychosocial stressors might influence CVD.

Researchers commonly invoke behavioral differences to explain socioeconomic inequalities in health status in general and in CVD in particular. Emphasis on behavioral factors remains controversial, and several major studies indicate that although behavioral differences contribute to socioeconomic inequalities, they do not explain the majority of the differences [11, 65-67]. More recent studies, adopting new analytic methodologies, suggest prior work may have underestimated the importance of common behaviors and that behaviors play a major role in some but not all countries $[8,68 \cdot, 69]$. The range in findings is difficult to interpret for a variety of reasons. One problem is that health behaviors are not randomly assigned in empirical studies, making causal inferences suspect. Another problem involves the ways behaviors are understood and defined; for example, obesity is often considered alongside so-called 'lifestyle' factors (such as physical activity or diet), despite the fact that obesity is neither precisely a behavior nor a lifestyle. Finally, it is likely that underlying health may determine behaviors such as physical activity, so mediation effect estimates are extremely vulnerable to bias from confounding of the mediator and outcome. As with the challenges in life-course epidemiology, the magnitude of statistical challenges in mediation analysis has recently received substantial attention [70-72], but little empirical work has been completed to address the bias in socioeconomic inequalities research. Despite the methodologic challenges, there is little debate that health behaviors are important mediators of socioeconomic inequalities in CVD - the uncertainty is only a matter of degree. The major question that remains is why health behaviors are so strongly patterned by SES. The health behaviors of both high- and low-SES individuals reflect interpersonal and social expectations of their family and friends, and access to resources such as money, time, and support $[9,10]$. More subtly, behaviors are pervasively structured by 'defaults' set up in the neighborhoods, workplaces, schools, and other settings of our lives [11, 12•].

Socioeconomic status influences psychological experiences, and a substantial body of literature has documented the links between adverse social position, life stress, low rank in social hierarchies, racism, and disadvantaged living and working conditions and the functioning of the limbic system and stress responses. Exposure to psychosocial stressors may 
cause disease relatively directly; for example, though activation of the sympathetic nervous system (SNS) and hypothalamic-pituitary-adrenal axis (HPAA), leading to chronic sympathetic stimulation and hypertension [73, 74]. The effect may also be indirect, with stressors increasing rates of adverse health behaviors, or inducing anxiety or depression. In behavioral medicine, acute and chronic triggers are considered to be distinct in relation to stress. The physiologic response to perceived threat is an evolutionarily adaptive 'fight or flight' response, but can be triggered by either physical or psychological threats. SNS and HPAA activation is associated with platelet activation, endothelial dysfunction, hypertension, immune system suppression, inflammation, and changes in cardiac cellular electrophysiology. Repeated exposure to stressors associated with socioeconomic disadvantage has been hypothesized to eventually overwhelm the body's ability to recovery after threatening episodes, leading to accumulation of 'allostatic load' that increases CVD risk [75]. Sudden death, most often caused by ventricular fibrillation and highly associated with coronary disease and MI, is unsurprisingly associated with SES as well as depression [76-78]. The occurrence of sudden death may reflect both kinds of stress events; chronic insult resulting in the substrate for arrhythmia, and an acute stress trigger of a cardiac arrest [79].

A large body of evidence implicates intra-uterine conditions in adult CVD risk. This research was motivated by the observation that low birth weight, defined as weight $<2500 \mathrm{~g}$ at birth, is a strong and consistent predictor of CVD [80, 81]. The adverse consequences of intrauterine growth restriction gave rise to the 'fetal origin' theory: intrauterine factors modify fetal growth and alter susceptibility to other environmental risk factors encountered across the life course. Findings from surveys of famine in varying populations have further exposed the crucial concept of timing of varying exposures. Individuals who were in utero during the Dutch Famine winter at the end of the Second World War had greater risk of coronary heart disease compared with those who were in utero either right before or right after the famine [82]. In contrast, individuals exposed to famine during fetal development during the Siege of Leningrad did not develop obesity. The contrast between the long-term outcomes among individuals exposed to the Dutch Famine and the Siege of Leningrad is presumed to be due to the continuance of nutritional deprivation in Leningrad even after the end of the siege compared with the post-war situation in the Netherlands [83]. Overall, nutritional scarcity in the mother leads to a reduction in nephron number in the kidneys, reduced cell growth in the pancreas, decreased insulin sensitivity, up-regulation of the hypothalamicpituitary-adrenal axis, and vascular dysfunction, all of which likely play important roles in the association of low birth weight with hypertension, diabetes, and coronary artery disease [84].

\section{Next Steps: Research and Translation}

The most important questions in research on socioeconomic determinants of CVD relate to how we translate from the evidence to reductions in CVD. To identify effective translational interventions, we need first to establish which socioeconomic factors are causal and which are non-causal correlates of CVD. Causal inference regarding the effects of social determinants of health is challenging, because social disadvantage tends to cluster, so it is difficult to isolate the effect of, for example, having low education from living in a lowincome community. If we want to try to design effective interventions, however, it is very important to try to distinguish which specific modifiable factors will elicit reductions in CVD risk. Some powerful and still under-used research tools for causal inference in social epidemiology include migration studies and quasi-experimental designs. As an example of the latter, one can assess differences in outcomes based on sudden public policy changes or lotteries $[85,86]$.

Designing effective interventions also entails knowing when and how we can change the exposure of interest. Social conditions are difficult to change and may take months, years, or decades to modify substantially. Identifying the primary mechanisms linking social factors and CVD can help guide intervention design. As we learn why people born in some places have elevated CVD risk, we enhance the ability to design upstream population health interventions interrupting these pathways. Further, we may be able to use information on social conditions to identify individuals who are at high risk of adverse events, and prioritize these individuals for preventive interventions [87]. In fact, using social information to enhance predictive modeling may be a simple application with major benefits to the most vulnerable populations, even if it fails to address the underlying causes of inequality. Although socioeconomic inequalities in health prevail in situations with essentially equal access to high-quality medical care, the healthcare delivery system may be an important avenue for addressing social inequalities [88]. For example, community health workers have served as an important bridge to address social disparities and help patients obtain needed care $[89,88]$. Disparities in quality of care surely $d o$ contribute to social inequalities and public health-clinical partnerships may be necessary to address disparities [88].

\section{Conclusions}

The promise of epidemiology is to improve public health and prevent suffering and disease by using the patterns of disease occurrence to understand why disease is occurring. When social variations in a disease pattern are observed, these inequalities suggest that there is very likely a modifiable contribution to disease. Social inequalities represent a tragedy, but 
they also indicate areas of opportunity for reducing CVD. Translating the findings on social inequalities in CVD from academic research results into public health interventions will require an iterative engagement between observational and interventional research. Current evidence suggests that the most effective intervention strategies will target early in life and address both individual and contextual factors that shape conventional cardiovascular risk factors.

Acknowledgements The authors gratefully acknowledge support from the National Institute on Aging (K08AG032357 and R21AG34385), the American Heart Association (10SDG2640243). Dr Patton additionally received support from the John L. Locke Jr. Charitable Trust.

\section{Compliance with Ethics Guidelines}

Conflict of Interest MM Glymour declares no conflicts of interest. CR Clark declares no conflicts of interest.

KK Patton declares no conflicts of interest.

Human and Animal Rights and Informed Consent All studies by KK Patton involving animal and/or human subjects were performed after approval by the appropriate institutional review boards. When required, written informed consent was obtained from all participants.

\section{References}

Papers of particular interest, published recently, have been highlighted as:

- Of importance

1. Kaplan GA, Keil JE. Socioeconomic factors and cardiovascular disease: a review of the literature. Circulation. 1993;88(4):1973-98.

2. Galea S, Tracy M, Hoggatt KJ, DiMaggio C, Karpati A. Estimated deaths attributable to social factors in the United States. Am J Public Health. 2011;101(8):1456-65.

3. Galobardes B, Smith GD, Lynch JW. Systematic review of the influence of childhood socioeconomic circumstances on risk for cardiovascular disease in adulthood. Ann Epidemiol. 2006;16(2):91-104.

4. Manrique-Garcia E, Sidorchuk A, Hallqvist J, Moradi T. Socioeconomic position and incidence of acute myocardial infarction: a meta-analysis. J Epidemiol Community Health. 2011;65(4):301-9.

5. Krieger N, Rehkopf DH, Chen JT, Waterman PD, Marcelli E, Kennedy M. The fall and rise of US inequities in premature mortality: 1960-2002. PLoS Med. 2008;5(2):e46.

6. Avendano M, Glymour MM, Banks J, Mackenbach JP. Health disadvantage in US adults aged 50 to 74 years: a comparison of the health of rich and poor Americans with that of Europeans. Am J Public Health. 2009;99(3):540-8.

7. Nandi A, Glymour MM, Subramanian SV. Association among socioeconomic status, health behaviors, and all-cause mortality in the United States. Epidemiology. 2014;25(2):170-7. doi:10.1097/ EDE.0000000000000038.

8. Stringhini S, Sabia S, Shipley M, Brunner E, Nabi H, Kivimaki M, et al. Association of socioeconomic position with health behaviors and mortality. JAMA. 2010;303(12):1159-66.
9. Emmons KM. Health behaviors in a social context. In: Berkman LF, Kawachi I, editors. Social epidemiology. New York: Oxford University Press; 2000. p. 242-66.

10. Graham H. Women's smoking and family health. Soc Sci Med. 1987;25(1):47-56.

11. Lynch JW, Kaplan GA, Salonen JT. Why do poor people behave poorly? Variation in adult health behaviours and psychosocial characteristics by stages of the socioeconomic lifecourse. Soc Sci Med. 1997;44(6):809-19.

12. Thorgeirsson T, Kawachi I. Behavioral economics: merging psychology and economics for lifestyle interventions. Am J Prev Med. 2013;44(2):185-9. Argues for incorporating ideas from behavioral economics into design and implementation of health behavior interventions.

13. Williams DR, Mohammed SA, Leavell J, Collins C. Race, socioeconomic status, and health: complexities, ongoing challenges, and research opportunities. Ann N Y Acad Sci. 2010;1186(1):69-101.

14. Lewis TT, Williams DR, Tamene M, Clark CR. Self-reported experiences of discrimination and cardiovascular disease. Curr Cardiovasc Risk Rep. 2014;8(1):1-15. Reviews the literature describing the role of perceived discrimination as a determinant of CVD risk.

15. Kubzansky L, Kawachi I. Affective states and health. In: Berkman LF, Kawachi I, editors. Social epidemiology. New York: Oxford University Press; 2000. p. 213-41.

16. Berkman LF, Glass TA. Social integration, social networks, social support, and health. In: Berkman LF, Kawachi I, editors. Social epidemiology. New York: Oxford University Press; 2000. p. 137-73.

17. Everson-Rose SA, Lewis TT. Psychosocial factors and cardiovascular diseases. Annu Rev Public Health. 2005;26(1):469-500. doi: 10.1146/annurev.publhealth.26.021304.144542.

18. Nazmi A, Victora CG. Socioeconomic and racial/ethnic differentials of C-reactive protein levels: a systematic review of populationbased studies. BMC Public Health. 2007;7(1):212.

19. Braveman PA, Cubbin C, Egerter S, Chideya S, Marchi KS, Metzler M, et al. Socioeconomic status in health research-one size does not fit all. JAMA. 2005;294(22):2879-88.

20. Glymour MM, Benjamin EJ, Kosheleva A, Gilsanz P, Curtis LH, Patton KK. Early life predictors of atrial fibrillation-related mortality: evidence from the health and retirement study. Health Place. 2013;21:133-9. doi:10.1016/j.healthplace.2012.12.008.

21. Phelan JC, Link BG, Tehranifar P. Social conditions as fundamental causes of health inequalities: theory, evidence, and policy implications. J Health Soc Behav. 2010;51(1 suppl):S28-40. doi:10.1177/ 0022146510383498.

22. Link BG, Phelan J. Social conditions as fundamental causes of disease. J Health Social Behav. 1995; Spec:80-94.

23. Link BG, Northridge ME, Phelan JC, Ganz ML. Social epidemiology and the fundamental cause concept: on the structuring of effective cancer screens by socioeconomic status. Milbank Q. 1998;76(3):375-402.

24. Kuh D, Ben-Shlomo Y, editors. A lifecourse approach to chronic disease epidemiology: tracing the origins of ill-health from early to adult life. Oxford: Oxford University Press; 1997.

25. Pollitt RA, Rose KM, Kaufman JS. Evaluating the evidence for models of life course socioeconomic factors and cardiovascular outcomes: a systematic review feedback. BMC Public Health. 2005;5:7.

26. Buckley T, McKinley S, Tofler G, Bartrop R. Cardiovascular risk in early bereavement: a literature review and proposed mechanisms. Int J Nurs Stud. 2009;42(2):229-38.

27. Shah SM, Carey IM, Harris T, DeWilde S, Victor CR, Cook DG. Impact of partner bereavement on quality of cardiovascular disease management. Circulation. 2013;128(25):2745-53.

28. Howard VJ, McClure LA, Glymour MM, Cunningham SA, Kleindorfer DO, Crowe M, et al. Effect of duration and age at 
exposure to the Stroke Belt on incident stroke in adulthood. Neurology. 2013;80(18):1655-61. Evaluates possible sensitive periods of exposure to the Stroke Belt for effects on later-life stroke incidence; implicates early life through adolescence.

29. Glymour M, Kosheleva A, Boden-Albala B. Birth and adult residence in the stroke belt independently predict stroke mortality. Neurology. 2009;73(22):1858-65.

30. Glymour MM, Avendano M, Berkman LF. Is the 'stroke belt' worn from childhood?: risk of first stroke and state of residence in childhood and adulthood. Stroke. 2007;38(9):2415-21. doi:10. 1161/STROKEAHA.107.482059.

31. Nandi A, Glymour M, VanderWeele T. Using marginal structural models to estimate the direct effect of adverse childhood social conditions on onset of heart disease, diabetes, and stroke. Epidemiology. 2012;23(2):223.

32. Mishra GD, Chiesa F, Goodman A, De Stavola B, Koupil I. Socioeconomic position over the life course and all-cause, and circulatory diseases mortality at age 50-87 years: results from a Swedish birth cohort. Eur J Epidemiol. 2013;28(2):139-47.

33. Yeung EH, Robledo C, Boghossian N, Zhang C, Mendola P. Developmental origins of cardiovascular disease. Curr Epidemiol Rep 2014:1-8.

34. Holford TR, Levy DT, McKay LA, Clarke L, Racine B, Meza R, et al. Patterns of birth cohort - specific smoking histories, 19652009. Am J Prev Med. 2014;46(2):e31-7.

35. Wilkinson AV, Spitz MR, Strom SS, Prokhorov AV, Barcenas CH, Cao Y, et al. Effects of nativity, age at migration, and acculturation on smoking among adult Houston residents of Mexican descent. Am J Public Health. 2005;95(6).

36. Kimbro RT. Acculturation in context: gender, age at migration, neighborhood ethnicity, and health behaviors. Soc Sci Q. 2009;90(5):1145-66. doi:10.1111/j.1540-6237.2009.00651.x.

37. Roshania R, Narayan K, Oza-Frank R. Age at arrival and risk of obesity among US immigrants. Obesity. 2008;16(12):2669-75.

38. Pudrovska T, Anikputa B. Early-life socioeconomic status and mortality in later life: an integration of four life-course mechanisms. J Gerontol Ser B Psychol Sci Soc Sci. 2014. doi:10.1093/geronb/gbt122.

39. Mishra G, Nitsch D, Black S, De Stavola B, Kuh D, Hardy R. A structured approach to modelling the effects of binary exposure variables over the life course. Int J Epidemiol. 2009;38(2):52837. Proposes a formal regression approach for evaluating alternative life-course models.

40. Taubman SL, Robins JM, Mittleman MA, Hernan MA. Intervening on risk factors for coronary heart disease: an application of the parametric g-formula. Int J Epidemiol. 2009;38(6):1599-611.

41. Diez-Roux AV, Merkin SS, Arnett D, Chambless L, Massing M, Nieto FJ, et al. Neighborhood of residence and incidence of coronary heart disease. N Engl J Med. 2001;345(2):99.

42. Lee RE, Cubbin C. Neighborhood context and youth cardiovascular health behaviors. Am J Public Health. 2002;92(3):428-36.

43. Brown AF, Liang L-J, Vassar SD, Stein-Merkin S, Longstreth WT, Ovbiagele B, et al. Neighborhood disadvantage and ischemic stroke: the Cardiovascular Health Study (CHS). Stroke. 2011;42(12):3363-8. doi:10.1161/strokeaha.111.622134.

44. Osypuk TL, Diez Roux AV, Hadley C, Kandula NR. Are immigrant enclaves healthy places to live? The multi-ethnic study of atherosclerosis. Soc Sci Med. 2009;69(1):110-20.

45. Larson N, Story M. A review of environmental influences on food choices. Ann Behav Med. 2009;38 Suppl 1:S56-73.

46. Walker R, Block J, Kawachi I. Do residents of food deserts express different food buying preferences compared to residents of food oases? A mixed-methods analysis. Int J Behav Nutr Phys Act. 2012;9(1):41.

47. Osypuk TL, Galea S. What level macro? Choosing appropriate levels to assess how place influences population health. In: Galea
S, editor. Macrosocial determinants of health. New York: Springer Media; 2007.

48. Mozaffarian D, Afshin A, Benowitz NL, Bittner V, Daniels SR, Franch HA, et al. Population approaches to improve diet, physical activity, and smoking habits. Circulation. 2012. doi:10.1161/CIR. 0b013e318260a20b.

49. Hawkins NM, Jhund PS, McMurray JJ, Capewell S. Heart failure and socioeconomic status: accumulating evidence of inequality. Eur J Heart Fail. 2012;14(2):138-46. doi:10.1093/eurjhf/hfr168 hfr168.

50. Pollitt RA, Rose KM, Kaufman JS. Evaluating the evidence for models of life course socioeconomic factors and cardiovascular outcomes: a systematic review. BMC Public Health. 2005;5:7. doi:10.1186/1471-2458-5-7.

51. Harper S, Lynch J. Trends in socioeconomic inequalities in adult health behaviors among U.S. states, 1990-2004. Public Health Rep. 2007;122(2):177-89.

52. Addo J, Ayerbe L, Mohan KM, Crichton S, Sheldenkar A, Chen R, et al. Socioeconomic status and stroke: an updated review. Stroke. 2012;43(4):1186-91. doi:10.1161/STROKEAHA.111. 639732STROKEAHA.111.639732.

53. Rosengren A, Subramanian S, Islam S, Chow CK, Avezum A, Kazmi K, et al. Education and risk for acute myocardial infarction in 52 high, middle and low-income countries: INTERHEART casecontrol study. Heart. 2009;95(24):2014-22.

54. Goyal A, Bhatt DL, Steg PG, Gersh BJ, Alberts MJ, Ohman EM, et al. Attained educational level and incident atherothrombotic events in low- and middle-income compared with high-income countries. Circulation. 2010;122(12):1167-75. doi:10.1161/ circulationaha.109.919274.

55. Fleischer NL, Diez Roux AV, Hubbard AE. Inequalities in body mass index and smoking behavior in 70 countries: evidence for a social transition in chronic disease risk. Am J Epidemiol. 2012;175(3):167-76. doi:10.1093/aje/kwr314.

56. Subramanian S, Corsi DJ, Subramanyam MA, Davey Smith G. Jumping the gun: the problematic discourse on socioeconomic status and cardiovascular health in India. Int $\mathrm{J}$ Epidemiol. 2013;42(5):1410-26. doi:10.1093/ije/dyt017.

57. Stringhini S, Bovet P. Commentary: the social transition of cardiovascular disease in low- and middle-income countries: wait and see is not an option. Int $\mathbf{J}$ Epidemiol. 2013;42(5):1429-31. doi: 10.1093/ije/dyt084.

58. Mackenbach JP. The persistence of health inequalities in modern welfare states: the explanation of a paradox. Soc Sci Med. 2012;75(4):761-9. doi:10.1016/j.socscimed.2012.02.031.

59. Feigin VL, Lawes CM, Bennett DA, Barker-Collo SL, Parag V. Worldwide stroke incidence and early case fatality reported in 56 population-based studies: a systematic review. Lancet Neurol. 2009;8(4):355-69.

60. Harper S, Lynch J, Smith GD. Social determinants and the decline of cardiovascular diseases: understanding the links. Annu Rev Public Health. 2011;32:39-69. doi:10.1146/annurev-publhealth031210-101234.

61. Lindenauer PK, Lagu T, Rothberg MB, Avrunin J, Pekow PS, Wang Y, et al. Income inequality and 30 day outcomes after acute myocardial infarction, heart failure, and pneumonia: retrospective cohort study. BMJ. 2013;346:f521. doi:10.1136/bmj.f521bmj.f521.

62. Chen JT, Beckfield J, Waterman PD, Krieger N. Can changes in the distributions of and associations between education and income bias temporal comparisons of health disparities? An exploration with causal graphs and simulations. Am J Epidemiol. 2013;177(9): 870-81. doi:10.1093/aje/kwt041.

63. Bobak M, Marmot M. Societal transition and health. Lancet. 2009;373(9661):360-2. doi:10.1016/S0140-6736(09)60043-X.

64. Marmot MG, Rose G, Shipley M, Hamilton PJ. Employment grade and coronary heart disease in British civil servants. J Epidemiol Community Health. 1978;32(4):244-9. 
65. Rose G, Marmot MG. Social class and coronary heart disease. $\mathrm{Br}$ Heart J. 1981;45(1):13-9.

66. Lantz PM, House JS, Lepkowski JM, Williams DR, Mero RP, Chen JM. Socioeconomic factors, health behaviors, and mortality - results from a nationally representative prospective study of US adults. JAMA. 1998;279(21):1703-8.

67. Laaksonen M, Talala K, Martelin T, Rahkonen O, Roos E, Helakorpi S, et al. Health behaviours as explanations for educational level differences in cardiovascular and all-cause mortality: a follow-up of 60000 men and women over 23 years. Eur J Public Health. 2008;18(1):38-43. doi:10.1093/eurpub/ckm051.

68. Nandi A, Glymour MM, Subramanian S. Association among socioeconomic status, health behaviors, and all-cause mortality in the United States. Epidemiology. 2014;25(2):170-7. Implements marginal structural models to correctly account for the effects of early life SES on adult behavioral factors.

69. Stringhini S, Dugravot A, Shipley M, Goldberg M, Zins M, Kivimäki M, et al. Health behaviours, socioeconomic status, and mortality: further analyses of the British Whitehall II and the French GAZEL prospective cohorts. PLoS Med. 2011;8(2):e1000419. doi: 10.1371/journal.pmed.1000419.

70. Cole SR, Hernán MA. Fallibility in estimating direct effects. Int J Epidemiol. 2002;31(1):163-5.

71. Kaufman J, Maclehose R, Kaufman S. A further critique of the analytic strategy of adjusting for covariates to identify biologic mediation. Epidemiol Perspect Innov. 2004;1(1):4.

72. Robins JM, Greenland S. Identifiability and exchangeability for direct and indirect effects. Epidemiology. 1992;3(2):143-55.

73. Steptoe A, Kivimäki M. Stress and cardiovascular disease: an update on current knowledge. Annu Rev Public Health. 2013;34(1):337-54. doi:10.1146/annurev-publhealth-031912-114452.

74. Steptoe A, Marmot M. The role of psychobiological pathways in socio-economic inequalities in cardiovascular disease risk. Eur Heart J. 2002;23(1):13-25.

75. Seeman T, Epel E, Grueewald T, Karlamangla AS, McEwen BS. Socio-economic differentials in peripheral biology: cumulative allostatic load. Ann N Y Acad Sci. 2010;1186:223-39.

76. Whang W, Kubzansky LD, Kawachi I, Rexrode KM, Kroenke CH, Glynn RJ, et al. Depression and risk of sudden cardiac death and coronary heart disease in women results from the Nurses' Health Study. J Am Coll Cardiol. 2009;53(11):950-8. doi:10.1016/j.jacc. 2008.10.060.

77. Hemingway H, Malik M, Marmot M. Social and psychosocial influences on sudden cardiac death, ventricular arrhythmia and cardiac autonomic function. Eur Heart J. 2001;22(13):1082-101. doi:10.1053/euhj.2000.2534.
78. Reinier K, Stecker EC, Vickers C, Gunson K, Jui J, Chugh SS. Incidence of sudden cardiac arrest is higher in areas of low socioeconomic status: a prospective two year study in a large United States community. Resuscitation. 2006;70(2):186-92. doi:10.1016/ j.resuscitation.2005.11.018.

79. Chugh SS, Reinier K, Teodorescu C, Evanado A, Kehr E, Al Samara M, et al. Epidemiology of sudden cardiac death: clinical and research implications. Prog Cardiovasc Dis. 2008;51(3):213-28.

80. Barker DJ, Eriksson JG, Forsen T, Osmond C. Fetal origins of adult disease: strength of effects and biological basis. Int J Epidemiol. 2002;31(6):1235-9.

81. Risnes KR, Vatten LJ, Baker JL, Jameson K, Sovio U, Kajantie E, et al. Birthweight and mortality in adulthood: a systematic review and meta-analysis. Int J Epidemiol. 2011;40(3):647-61.

82. Roseboom TJ, van der Meulen JH, Osmond C, Barker DJ, Ravelli AC, Schroeder-Tanka JM, et al. Coronary heart disease after prenatal exposure to the Dutch famine, 1944-45. Heart. 2000;84(6):595-8.

83. Stanner SA, Bulmer K, Andres C, Lantseva OE, Borodina V, Poteen $\mathrm{VV}$, et al. Does malnutrition in utero determine diabetes and coronary heart disease in adulthood? Results from the Leningrad siege study, a cross sectional study. BMJ. 1997;315(7119):1342-8.

84. Ligi I, Grandvuillemin I, Andres V, Dignat-George F, Simeoni U, editors. Low birth weight infants and the developmental programming of hypertension: a focus on vascular factors. Seminars in Perinatology. Elsevier; 2010.

85. Franco M, Orduñez P, Caballero B, Tapia Granados JA, Lazo M, Bernal JL, et al. Impact of energy intake, physical activity, and population-wide weight loss on cardiovascular disease and diabetes mortality in Cuba, 1980-2005. Am J Epidemiol. 2007;166(12): 1374-80. doi:10.1093/aje/kwm226.

86. Jürges H, Kruk E, Reinhold S. The effect of compulsory schooling on health-evidence from biomarkers. J Popul Econ. 2013;26(2):645-72.

87. Patton KK, Glymour MM. In anticipation of grief using insights from social epidemiology to improve quality of care. Circulation. 2013;128(25):2725-8.

88. Primary Care and Public Health. Exploring integration to improve population health. The National Academies Press; 2012.

89. Clark CR, Baril N, Kunicki M, Johnson N, Soukup J, Ferguson K, et al. Addressing social determinants of health to improve access to early breast cancer detection: results of the Boston REACH 2010 Breast and Cervical Cancer Coalition Women's Health Demonstration Project. J Women's Health. 2009;18(5):677-90. 